\title{
Profitability of cultivation of raspberry variety Polka
}

\section{Opłacalność uprawy malin odmiany Polka}

\author{
Alicja Baranowska ${ }^{1}$, Krystyna Zarzecka², Katarzyna Świerczewska-Pietras ${ }^{1}$
}

\section{Summary}

Field experiments were conducted on commercial plantation with an area of 1 hectare between the years 2011-2013. The production was established on a sandy soil classified as IVb bonitation class. The research material consisted of data regarding a cultivation of an autumn raspberry variety Polka. The aim of the study was to determine the economic efficiency of Polka production on the basis of SGM (Standard Gross Margin). The results revealed that the production of raspberries in 2011-2013 was profitable. In the direct cost structure, the purchase of raspberry seedlings was one of the lowest expenses unlikely to some specific costs which covered labor hired to manual harvesting. Moreover, plant protection products as well as mineral fertilization shared significant fraction in the cost structure.

Key words: costs; profitability of cultivation; raspberry yield; gross margin

\section{Streszczenie}

Badania polowe przeprowadzono w latach 2011-2013 na plantacji produkcyjnej o powierzchni 1 ha, założonej na glebie lekkiej zaliczanej do klasy bonitacyjnej IVb. Materiał badawczy stanowiły dane dotyczące uprawy malin jesiennych odmiany Polka. Celem badań było określenie efektywności ekonomicznej uprawy malin na podstawie standardowej nadwyżki bezpośredniej (SGM - Standard Gross Margin). Stwierdzono, że produkcja malin w latach 2011-2013 była opłacalna. Wśród kosztów bezpośrednich największe były specjalistyczne, które obejmowały koszty najmu siły roboczej do ręcznego zbioru owoców, a najtańszy był zakup sadzonek malin. W strukturze kosztów bezpośrednich duży udział miały również koszty wykonanych zabiegów chemicznych oraz nawożenia mineralnego.

Słowa kluczowe: koszty; opłacalność uprawy; plon malin; nadwyżka bezpośrednia

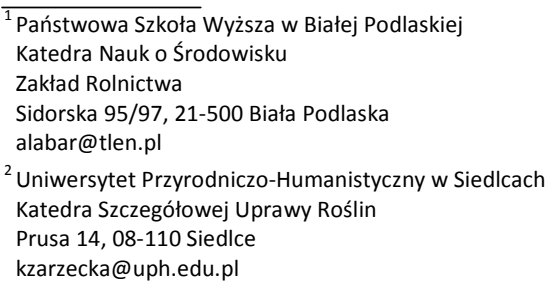




\section{Wstęp / Introduction}

Produkcja owoców jagodowych odgrywa ważną rolę w polskim sadownictwie. Łączne zbiory owoców z plantacji jagodowych i z krzewów owocowych w 2013 roku wyniosły 575 tys. $\mathrm{t}$ i były o 3,2\% większe od zbiorów z roku 2012 i o 12,3\% większe od przeciętnych zbiorów z lat 2006-2010 (Wynikowy szacunek 2013). Powierzchnia uprawy krzewów owocowych i plantacji jagodowych wynosiła 140 tys. ha, czyli 0,94\% areału użytków rolnych.

Maliny uprawiano na powierzchni 28 tys. ha, co stanowiło 0,18\% użytków rolnych (Rocznik Statystyczny Rolnictwa 2013). Powierzchnia jednej plantacji wahała się od 0,4 do 10 ha. Przeciętny plon malin z 1 ha w 2012 roku wyniósł 44,7 dt (Produkcja upraw rolnych). Jednak w 2013 roku odnotowano spadek produkcji malin o 4,8\% w stosunku do roku $2012 \mathrm{z}$ uwagi na gorsze plonowanie wynikające ze skrócenia okresu zbioru. Natomiast ceny malin przemysłowych wzrosły o $59 \%$, do $4,30 \mathrm{PLN} / \mathrm{kg}$ i był to poziom najwyższy $\mathrm{w}$ ostatnich sześciu latach. $\mathrm{O}$ wzroście cen malin zadecydowały niedobory przetworów $\mathrm{z}$ tych owoców na rynku światowym i europejskim, spowodowane niska podażą w 2012 i 2013 roku.

Wpływy z eksportu owoców malin w 2013 roku wzrosły o $35 \%$ do około $21 \mathrm{mln}$ euro, w wyniku zwiększenia z 0,93 do 1,3 euro/kg cen eksportowych. Wzrost cen eksportowych malin, spowodowany był głębokimi niedoborami przetworów $\mathrm{z}$ tych owoców na rynku europejskim w sezonie 2012/2013 (Rynek Owoców i Warzyw 2013).

Maliny są jedną $\mathrm{z}$ ważniejszych roślin sadowniczych klimatu umiarkowanego. Poza walorami odżywczymi i dietetycznymi posiadają również wartości lecznicze (Krauze-Baranowska i Majdan 2009). Owoce malin stanowią cenne źródło naturalnych antyoksydantów. Zawierają duże ilości cukrów prostych, barwników, są bogate w kwasy organiczne, między innymi salicylowy (główny składnik aspiryny), jabłkowy i cytrynowy, jak również w witaminy: C, E, A, PP, $\mathrm{B}_{1}, \mathrm{~B}_{2}, \mathrm{~B}_{3}$. Ponadto w owocach malin występują składniki mineralne: potas, fosfor, wapń, magnez, sód, a w mniejszych ilościach: cynk, miedź, żelazo i mangan. Nasiona zawierają substancje tłuszczowe, w skład których wchodzą kwasy tłuszczowe: linolowy, linolinowy, isolinolenowy oraz fitosterole. Wartość energetyczna 100 g owoców wynosi $130 \mathrm{~kJ}$, czyli $31 \mathrm{kcal}$ (Karabela 2007; Krauze-Baranowska i Majdan 2009). Owoce malin nadają się do bezpośredniego spożycia, są również bardzo dobrym surowcem dla przemysłu przetwórczego, który wprowadza nowe produkty, np. owoce puree czy smoothie (Winiarska i wsp. 2005; KrauzeBaranowska i Majdan 2009; Baranowska i Zarzecka 2012).

Zdaniem producentów do produkcji malin zachęca duże zapotrzebowanie na owoce deserowe i przeznaczone do przetwórstwa, a także niezawodność uprawy dzięki wprowadzeniu nowych odmian przystosowanych do krajowych warunków klimatyczno-glebowych (Danek 2005, 2009). W każdej uprawie podstawowymi czynnikami decydującymi o opłacalności uprawy są: uzyskana cena zbytu, wielkość plonów i poziom kosztów. Wśród kosztów znaczący udział mają koszty najemnej siły roboczej, zwłaszcza poniesione na zbiór owoców. Ponadto duży udział stanowia koszty wydatkowane na ochronę plantacji przed chorobami, szkodnikami i chwastami (Paszko 2006; Vetek i wsp. 2006; Brzozowski i Klimek 2010).

Celem badań było określenie opłacalności ekonomicznej uprawy malin odmiany Polka na podstawie standardowej nadwyżki bezpośredniej (SGM - Standard Gross Margin).

\section{Materiały i metody / Materials and methods}

Badania polowe przeprowadzono w latach 2011-2013 na plantacji produkcyjnej o powierzchni 1,0 ha. Plantację założono w 2010 roku na glebie wytworzonej z piasków gliniastych, kompleksu żytniego dobrego, klasy IVb, o pH (w KCl) 4,9, średniej zasobności w przyswajalny fosfor i niskiej w przyswajalny potas i magnez. Przedmiotem badań były owoce maliny jesiennej, odmiany Polka, powtarzającej owocowanie. Nasadzenia wykonano w rozstawie rzędów $3,0 \mathrm{~m} \times 0,5 \mathrm{~m}$. Jesienią wysiewano nawozy mineralne: fosforowe $\mathrm{P}-32,86\left(100 \mathrm{P}_{2} \mathrm{O}_{5} \times 0,44\right) \mathrm{kg} / \mathrm{ha}$ (superfosfat potrójny 46\%) i K - 112,10 (150 $\left.\mathrm{K}_{2} \mathrm{O} \times 0,83\right)$ $\mathrm{kg} / \mathrm{ha}$ (sól potasowa $60 \%$ ). Wiosną stosowano nawożenie azotowe (saletra amonowa 34\%) w dawce N $100 \mathrm{~kg} / \mathrm{ha}$, nawozy wapniowo-magnezowe (WapMag $\mathrm{CaO} 30 \%, \mathrm{MgO}$ $15 \%)$ w dawce $480 \mathrm{~kg} / \mathrm{ha}$ i nawóz wieloskładnikowy z mikroelementami Yara Mila Complex 12-11-18 (N $12 \%, \mathrm{P}-11 \%, \mathrm{~K}-18 \%, \mathrm{Mg}-2,7 \%, \mathrm{~S}-8 \%+$ mikroelementy) w dawce $300 \mathrm{~kg} / \mathrm{ha}$.

Zgodnie $\mathrm{z}$ zaleceniami ochrony roślin (Zalecenia 2012/2013) do ochrony plantacji przed szkodnikami: kistnikiem malinowcem (Byturus tomentosus F.), pryszczarkiem namalinkiem łodygowym (Reseliella theobaldi Barnes), kwieciakiem malinowcem (Anthonomus rubi Hbst.) i mszycami (Aphididae) stosowano insektycydy: Fastac 100 EC w dawce 0,18 1/ha i Karate Zenon 050 CS w dawce 0,3 1/ha. Przed chorobami grzybowymi (zamieranie pędów malin i szara pleśń) plantację chroniono preparatem Rovral Aquaflo $500 \mathrm{SC}$ w dawce 1,5 1/ha, następnie stosowano dwukrotne opryskiwanie fungicydem Teldor $500 \mathrm{SC}$ w dawce 1,5 1/ha. Chwasty zwalczano herbicydami: Kerb 500 SC w dawce 1,0 1/ha i Basta 200 SL w ilości 3,0 1/ha. Owoce malin zbierano ręcznie w fazie pełnej dojrzałości technologicznej, od pierwszej dekady sierpnia do drugiej dekady października. Średni plon owoców malin z 1 hektara wynosił $6250 \mathrm{~kg} / \mathrm{ha}$, a średnia cena $1 \mathrm{~kg}$ owoców malin wynosiła 3,0 PLN/kg. W kosztach bezpośrednich uwzględniono koszty sadzonek, nawozów mineralnych, środków ochrony roślin oraz koszty specjalistyczne (zabiegi chemiczne, zbiór ręczny malin). Srednie ceny materiałów i plonu przyjęto według cen zakupu i sprzedaży z lat 2011-2013. Wartość zbioru malin obliczono na podstawie iloczynu plonu i cen jednostkowej sprzedaży owoców. Koszty bezpośrednie stanowiły: sadzonki malin, środki ochrony roślin, nawozy mineralne oraz koszty specjalistyczne, które obejmowały najem siły roboczej do ręcznego zbioru malin oraz koszty wykonania zabiegów chemicznych. Efektywność ekonomiczną produkcji 1 ha malin określono kategorią nadwyżki bezpośredniej stanowiącej różnicę pomiędzy wartością 
rynkową plonu i kosztami bezpośrednimi obejmującymi zużycie materiałów oraz koszty specjalistyczne (Augustyńska-Grzymek i wsp. 2009).

\section{Wyniki i dyskusja / Results and discussion}

W Polsce produkcja owoców malin od wielu lat wykazuje tendencję wzrostową, ale obarczona jest dużym ryzykiem produkcyjnym (Kowalczyk 2006). W pracy przedstawiono efekt ekonomiczny uprawy jednego hektara malin odmiany Polka, uwzględniając: koszty bezpośrednie, wartość produkcji z 1 ha oraz nadwyżkę bezpośrednią (tab. 1).

Analizując koszty bezpośrednie stwierdzono, że relatywnie najmniejszą pozycję $\mathrm{w}$ układzie łącznym kosztów stanowił zakup sadzonek malin, wynosił on 1440,0 PLN/ha, (8,8\%) w strukturze kosztów (tab. 1). Największe były koszty specjalistyczne, które obejmowały najem siły roboczej do zbioru ręcznego malin. Wynosiły one 9800,0 PLN/ha, co stanowiło 59,8\% kosztów uprawy malin. W badaniach Rabcewicz i Wawrzyńczak (2006) koszt zbioru ręcznego owoców malin stanowił 80\% nakładów robocizny, a według Kowalczyka (2006) w gospodarstwach sadowniczych nakłady robocizny na 1 ha były trzykrotnie większe niż w gospodarstwach prowadzących typową produkcję rolniczą. W ostatnich latach prace hodowlane są ukierunkowane nie tylko na uzyskanie odmian o wysokiej jakości owoców, lecz również na przystosowanie do zbioru maszynowego (Danek 2005).
Koszt zakupu środków ochrony roślin wynosił 3168,0 PLN/ha i stanowił 19,3\% w strukturze kosztów bezpośrednich. Wśród środków ochrony roślin relatywnie najmniejszą pozycję w układzie łącznym kosztów stanowiły insektycydy $-1,6 \%$, natomiast największą fungicydy - 12,5\%, koszt herbicydów wynosił 5,2\% w strukturze kosztów bezpośrednich uprawy malin. Zdaniem Brzozowskiego (2003) koszty te można znacznie obniżyć poprzez ograniczenie liczby zabiegów ochrony.

Nawozy mineralne stanowiły średnio $12,1 \%$ w strukturze kosztów. Relatywnie największą pozycję w układzie łącznym kosztów stanowiło stosowanie nawozu mineralnego, wieloskładnikowego Yara Mila Complex 12-11$18(\mathrm{~N}-12 \%, \mathrm{P}-11 \%, \mathrm{~K}-18 \%, \mathrm{Mg}-2,7 \%, \mathrm{~S}-8 \%+$ mikroelementy) średnio 6,2\%. Zdaniem Smolarza (1996) stosując obornik można zmniejszyć dawki nawozów mineralnych przynajmniej $\mathrm{w}$ pierwszych latach prowadzenia plantacji. Obornik $w$ dawce $40-60$ t na 1 ha powinno się aplikować co 2-3 lata na plantacjach zlokalizowanych na glebach słabych, gdyż poza składnikami pokarmowymi wzbogaca on glebę w próchnicę i poprawia jej właściwości fizyczne oraz pojemność wodną.

Średnia wartość produkcji malin odmiany Polka wynosiła 18 750,0 PLN/ha, a nadwyżki bezpośredniej 2360,0 PLN/ha (bez dopłat bezpośrednich do produkcji owoców miękkich). Z powyższych obliczeń wynika, że produkcja malin jest opłacalna nawet przy średnim plonie, który zebrano z plantacji.

Tabela 1. Efekt ekonomiczny uprawy 1 ha maliny Polka (średnia z lat 2011-2013)

Table 1. The economic effect of the cultivation of 1 ha of raspberry Polka (average for 2011-2013)

\begin{tabular}{|c|c|c|c|c|c|}
\hline $\begin{array}{l}\text { Wyszczególnienie } \\
\text { Specification }\end{array}$ & $\begin{array}{l}\text { Jednostki } \\
\text { miary } \\
\text { Units }\end{array}$ & $\begin{array}{l}\text { Ilość } \\
\text { Number }\end{array}$ & $\begin{array}{c}\text { Cena } \\
\text { jednostkowa } \\
\text { Price per unit } \\
{[\text { PLN] }}\end{array}$ & $\begin{array}{l}\text { Wartość } \\
\text { Value } \\
\text { [PLN] }\end{array}$ & $\begin{array}{c}\text { Struktura } \\
\text { kosztów } \\
\text { The structure } \\
\text { cost } \\
{[\%]}\end{array}$ \\
\hline \multicolumn{6}{|l|}{ Koszty bezpośrednie - Direct costs: } \\
\hline Sadzonki z zakupu - Purchased seedlings $20 \%$ & $\begin{array}{l}\text { szt./ha } \\
\text { pcs/ha }\end{array}$ & 1200,0 & 1,2 & 1440,0 & 8,8 \\
\hline Razem nawozy mineralne - Total fertilizers: & \multicolumn{4}{|c|}{1982,0} & 12,1 \\
\hline - wapniowo-magnezowe - calcium and magnesium & \multirow{5}{*}{$\mathrm{kg} / \mathrm{ha}$} & 480,0 & 50,0 & 240,0 & 1,5 \\
\hline - wieloskładnikowe - multicomponent & & 300,0 & 340,0 & 1020,0 & 6,2 \\
\hline - azotowe - nitrogen & & 100,0 & 150,0 & 150,0 & 0,9 \\
\hline - fosforowe - phosphorus & & 100,0 & 287,0 & 287,0 & 1,8 \\
\hline - potasowe - potassium & & 150,0 & 190,0 & 285,0 & 1,7 \\
\hline Razem środki ochrony roślin - Total pesticides: & \multicolumn{4}{|c|}{3168,0} & 19,3 \\
\hline - fungicydy - fungicides & \multirow{3}{*}{ 1/ha } & 4,5 & 456,0 & 2052,0 & 12,5 \\
\hline - insektycydy - insecticides & & 3,2 & 80,0 & 256,0 & 1,6 \\
\hline - herbicydy - herbicides & & 4,0 & 215,0 & 860,0 & 5,2 \\
\hline Koszty specjalistyczne - Crop specific costs & \multirow{4}{*}{ PLN/ha } & - & - & 9800,0 & 59,8 \\
\hline $\begin{array}{l}\text { Ogółem koszty bezpośrednie na } 1 \text { ha } \\
\text { Total direct costs per } 1 \text { ha }\end{array}$ & & - & - & 16390,0 & 100 \\
\hline Wartość plonu malin - Value of raspberry yield & & - & - & 18750,0 & - \\
\hline Nadwyżka bezpośrednia - Gross margin & & - & - & 2360,0 & - \\
\hline
\end{tabular}

Źródło: opracowanie własne - Source: own calculations 


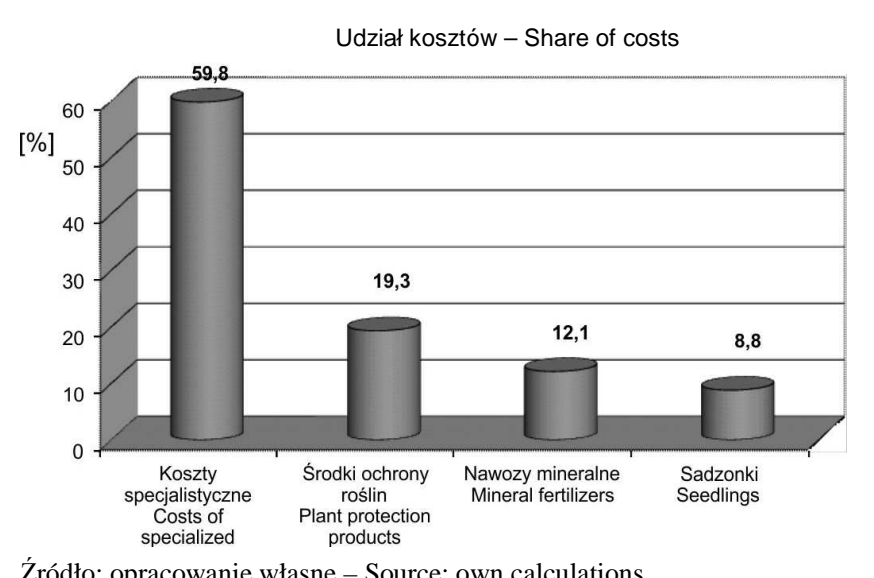

Źródło: opracowanie własne - Source: own calculations

Rys. 1. Struktura kosztów uprawy malin odmiany Polka (średnia z lat 2011-2013)

Fig. 1. The structure of production costs of Polka raspberry (average for 2011-2013)

\section{Wnioski / Conclusions}

1. W strukturze kosztów bezpośrednich uprawy malin odmiany Polka największe były koszty specjalistyczne, które stanowiły 59,8\% kosztów uprawy.

2. Udział środków ochrony roślin w strukturze kosztów bezpośrednich wynosił 19,3\%, relatywnie największą pozycję w układzie łącznym kosztów stanowiły fungicydy $-12,5 \%$.

3. Nawozy mineralne stanowiły $12,1 \%$ w strukturze kosztów. Relatywnie największą pozycję w układzie łącznym kosztów stanowiło stosowanie nawozu mineralnego, wieloskładnikowego - 6,2\% kosztów uprawy.

4. Uprawa 1 ha malin odmiany Polka była opłacalna.

\section{Literatura / References}

Augustyńska-Grzymek I., Cholewa M., Dziewulski M., Orłowski A., Skarżyńska A., Ziętek I., Zmarzłowski K. 2009. Produkcja, koszty i nadwyżka bezpośrednia wybranych produktów rolniczych w 2008 roku. Raport Programu Wieloletniego 140. IERiGŻ - PIB, Warszawa, $163 \mathrm{ss}$.

Baranowska A., Zarzecka K. 2012. Opłacalność uprawy malin. Rocz. Nauk. Stowarzyszenia Ekonomistów Rolnictwa i Agrobiznesu 14 (1): 26-28.

Brzozowski P., Klimek G. 2010. Opłacalność produkcji wiśni w Polsce w latach 2000-2010. Zesz. Nauk. Inst. Sad. Kwiac. 18: $181-193$.

Danek J. 2005. 25 lat hodowli maliny i jeżyny w Sadowniczym Zakładzie Doświadczalnym ISK w Brzeżnej. s. 165-166. W: Mat. X Ogólnopol. Nauk. Zjazdu Hodowców Roślin Ogrodniczych. „Zmienność genetyczna - utrzymanie, tworzenie i wykorzystanie w hodowli roślin”. Inst. Sad. Kwiac., Skierniewice, 15-16 lutego 2005, 192 ss.

Danek J. 2009. Uprawa maliny i jeżyny. Hortpress, Warszawa, 74 ss.

Karabela M. 2007. Malina. Panacea 3 (20): 30-31.

Kowalczyk Z. 2006. Poziom i struktura nakładów pracy w wybranych gospodarstwach sadowniczych. Inż. Roln. 11 (86): $209-214$.

Krauze-Baranowska M., Majdan M. 2009. Owoce malin - źródło cennych leczniczo metabolitów wtórnych i witamin. Panacea 1 (26): $14-15$.

Paszko D. 2006. Wybrane problemy rachunku ekonomicznego na przykładzie specjalistycznych gospodarstw sadowniczych województwa lubelskiego. Zesz. Nauk Inst. Sad. Kwiac. 14: 96-106.

Produkcja upraw rolnych i ogrodniczych w 2012 roku. Główny Urząd Statystyczny. Departament Rolnictwa. Warszawa, 2013,120 ss.

Rabcewicz J., Wawrzyńczak P. 2006. Możliwości zmechanizowania produkcji owoców z krzewów jagodowych. s. 81-92. W: Ogólnopol. Konf. Sadow. „Nowe odmiany i technologie uprawy krzewów jagodowych”. Inst. Sad. Kwiac., Skierniewice, 27 kwietnia 2006, 100 ss.

Rocznik Statystyczny Rolnictwa 2013. Główny Urząd Statystyczny, Warszawa, 425 ss.

Rynek Owoców i Warzyw. 2013. IERiGŻ 43: 7-18.

Smolarz K. 1996. Malina i jerzyna. PWRiL, Warszawa: 46-58.

Vetek G., Fail J., Penzes B. 2006. Susceptibility of raspberry cultivars to the raspberry cane midge (Resseliella theobaldi Barnes). J. Fruit Ornam. Plant Res. 14 (Suppl. 3): 61-66.

Winiarska J., Szember E., Żmuda E., Murawska D. 2005. Porównanie składu chemicznego owoców wybranych odmian maliny Rubus idaeus L. Ann. UMCS, Sec. E, 15: 293-303.

Wynikowy szacunek produkcji głównych ziemiopłodów rolnych i ogrodniczych w 2013 roku. Główny Urząd Statystyczny. Departament Rolnictwa, Warszawa 2013, 26 ss.

Zalecenia ochrony roślin na lata 2012/2013. Część III. Warzywa, sady. Inst. Ochr. Roślin - PIB, Poznań: 198-200. 